\title{
Relationship between Anthropometric parameters and Physical fitness in learners with visual impairment at the University of Jos
}

\author{
Article by Olawuwo S.O' ${ }^{1}$, Yakubu A.F ${ }^{2}$, Rasaki S.A3. \\ 1Physical Therapist, Department of Special Education \& Rehabilitation Sciences, \\ University of Jos Nigeria \\ ${ }^{2}$ Professor, Department of Special Education \& Rehabilitation Sciences, University of \\ Jos Nigeria \\ ${ }^{3}$ Chief Education Officer, Universal Basic Education Board (Special Need Education \\ Unit), Garki Abuja \\ Email:- olawuwo2001@gmail.com
}

\begin{abstract}
Physical activity plays an important role in prevention of chronic diseases; insight into the interaction between physical activity and health need to be quantified. The research goal was to investigate relationship between anthropometric parameters and physical fitness in learners with visual impairment. Twenty one male students with various degree of visual impairment participated (aged: 24-51 years) and tested on (1) six anthropometric predictors, including body weight, body height, body mass index (BMI), waist circumference, hip circumference and waist-to hip ratio (WHR), and (2) five Physical Fitness Factors (PFF) measuring: Heat rate, Systolic Blood Pressure, Diastolic Blood Pressure, right and left grip strength, flexibility and Aerobic endurance. Correlation and survey research design was adopted for the study. Descriptive statistic (mean, S.D) and inferential statistic (Pearson correlation and regression) were computed with SPSS version 20. Linear $(y=a+b x)$ and multiple linear $\left(y=a+b_{1} x_{1}+b_{2} x_{2} \ldots . . b_{n} x_{n}\right)$ equations were calculated to determine the degree of association and predict PFF from respective anthropometric variables. All anthropometric parameters produced an extremely weak relationship with physical fitness factors. In this study, no association is found between body weight and systolic blood pressure, no relationship between hip circumference and static right grip strength. Considering the goal of this research, it is concluded that there is a significant relationship between health's related anthropometric measure and physical fitness factors. Then we can use these measurements to predict values in any of the physical fitness components because the techniques are non-invasive and cost effective.
\end{abstract}

Key words: physical fitness, waist to hip ratio, anthropometric, flexibility.

\section{Introduction}

Health is defined by the World Health Organization as a state of complete physical, mental and social wellbeing, not merely the absence of disease or infirmity. Physical fitness has a close link with physical health, without health one cannot gain full physical fitness (Jaafari, 2012). Anthropometry is from a branch of science called "anthropology", it is anon invasive method to measure different part of the body, in terms of size, proportion and composition of the human body. Moreover, since the growth in children and body dimensions at all ages reflect the overall health and welfare of individuals and populations, anthropometry may also be use to predict performance, health and survivals (WHO, 1998)

Taylor, Mazzone and Wnutniak (2005) emphasized that the influence of morphological status on different performance variables are known to be directly related to overall physical routine, health status, and in independent living and quality of life. Physiological indices or profiles are markers that could predict presence or absence of major disease or illness.

Despite global awareness and interest in physical fitness for everyone, opportunities for people with disabilities in fitness programs remain quite limited (Miller, 1995), especially in 
South American Journal of Academic Research

Special Edition May 2016

developing nations with higher dismal picture. Earlier researcher has shown that children who are impaired consistently exhibited lower levels of fitness than their sighted peers (Blessing \& Mccrimmon, 1993). In the same vein, studies have regularly investigated the influence of different anthropometric dimensions and measures in relation to physical performance variable (Keogh, Hume, Pearson \& Mellow, 2009). In this part of the world there is dearth of empirical studies to show this clear assumption especially among the visually impaired.

Visual Impairment (VI) is a global public health problem (Thylefor \& Negrel, 1995), which at the same time need urgent global attention. According to WHO fact sheet release in June 2012, 28 million people are visually impaired in the world: 39 million are blind and 246 million have low vision. About 90 percent of the world's visual impaired live in developing countries.

There are five components of Physical Fitness (PF) (Heyward, 2002). This include: cardiopulmonary endurance, muscular fitness, body weight and composition, flexibility and neuromuscular relaxation. There is need to increase awareness of physical activity for optimal health and longevity among learners with visual impairment. Two major evaluation techniques to assess PF include field testing and laboratory method. Measures such as body weight, height, body mass index, waist-to-hip ratio, waist circumference, skin fold measurement are anthropometric in nature.

The basic anthropometry measurements are weight and height. Anthropometric indices are combinations of measurements. They are essential for the interpretation of measurements. It is evident that a value for body weight (BW) alone has no meaning unless it is related to an individual's age or height (WHO, 1995). Weight and height may be combined to produce the body mass index (Wt/ Ht2) or a Pondera index (Wt/ Ht3), or weight may be related to height through the use of reference data. BMI is a good indicator of variability in energy reserves in individuals with sedentary lifestyles.

Lieberman (2002) reiterate that children who are visually impaired consistently exhibit lower levels of fitness than sighted peers. The need for fitness in children who are blind might be greater because of increased energy to complete activity of daily living (Bueli, 1982).

Fogelholm, Malmberg, Suni, Santtila, Kyrolainen and Mantysaari (2005) observed that waist circumference(WC) and body mass index(BMI) are independently associated with variation of cardio respiratory and neuromuscular fitness in young adult men while Lasla (2012) opined that health related anthropometric measure correlate with physical fitness factor, he concluded that the measure can be used to predict function in physical and motor test since his finding reveals a negative significant correlation between health and anthropometric measures.

Colak and colleagues (2004), verify the effect of plying goal ball on some measures of motor fitness. 103 male visual impaired children, age 13-15 years with varying degree of blindness were assessed for motor fitness. All participants underwent motor fitness (balance, handgrip, flexibility, vertical jump, isokinetic concentric peak torque). They found a significant difference between goal ball player and non-goal ball players regarding many motor fitness components. The non-goal ball players were inferior in all motor fitness compared with goal ball players. The study is significant to individual with one disability or the other especially children with special needs.

It is a common thing for newly admitted students of tertiary institutions in Nigeria to undergo health screening as a final prerequisite for admission. During this exercise all vital signs as well as past medical history will be carefully screened through a checklist. Yet, experience has shown that there is no provision for further follow-up to ascertain candidate physical fitness during their studies and after graduation.

In the light of the above, there is need to understand basic anthropometric and physical fitness factors measurement which will help in ascertaining baseline physical activity levels of those with visual impairment in this community before any major critical intervention will be adopted. 


\section{Method}

The study adopted the correlation and survey research designs with a view to show relationship between anthropometric parameters (body weight, body height, body mass index, waist circumference, waist-to-hip ratio) and physical fitness factors (Flexibility, Heart rate, Blood pressure, Muscle endurance and Aerobic endurance).

The target group for this study was the male students of University of Jos, who have visually impairme. These were verified through their medical file submitted to the department or in their possession. The population of the study comprised of twenty one students (age range 27-51) with visual impairment in the undergraduate and diploma programs of the University of Jos.

The purposive sampling was used to select the sample for the study. The Anthropometric fitness (ANTHFIT) spread sheet was design by the researcher to collate both anthropometric parameters and physical fitness factors measurement. The study protocol was explained to the participant before given them written consent.

Anthropometric Parameters: Body Height was measured to the nearest $0.5 \mathrm{~cm}$ without shoes using a stadiometer for height and mounted scale for weight. Body weight was measured to the nearest $0.5 \mathrm{~cm}$ alongside the height after removal of shoes and wearing a light clothing only, using a mechanical beam balance mounted scale on the stadiometer. Body Mass Index (BMI), was calculated by putting the numbers related to height and weight in the equation $\left(w t / h t^{2}\right)$. Waist Circumference, Hip circumference was measured using a measuring tape.

Physical Fitness Factors: Flexibility was measured with the use of sit and reach box or flexibility box of $30.5 \mathrm{~cm}$ high. Heart rate was measured with the use of Stop Watch. Blood Pressure was measured in a seated position with mercury Sphygmomanometer and stethoscope. Aerobic endurance test was measured with the use of Queens's college step test which has a bench of height 161/4 inch. Muscle endurance was tested using Hand grip dynamometer.

The content validity of the instruments was ascertained by the supervisor as well as experts in test and measurement. The criterion related validity of the mechanical Beam balance to measure weight was sought by comparing the reading with bathroom scale using between 1015 students and then computed the validity coefficient. Mercury sphygmomanometer was compared with digital apparatus to ensure criterion related validity and validity coefficient computed.

The test -retest reliability was carried out as most of the measurement was taken twice or thrice to establish stability of the instrument. Such include the use of measuring tape for circumferences, stop watch for heart rate; sit-reach box for flexibility and sphygmomanometer for blood pressure.

Data collection took place at the Rehabilitation Laboratory of the Department of Special Education. Each student was given a consent form to ensure their free participation. Their right of confidentiality was ensured. Body Height was measured to the nearest $0.5 \mathrm{~cm}$ without shoes using a stadiometer for height and mounted scale for weight. The equipment is from a Chinese company. Each participant stood with heels, buttocks and shoulders resting lightly against the backing board so that the Frankfort plane (a line connecting the superior border of the external auditory meatus with the infraorbital rim) was horizontal (i.e. parallel to the floor).

Body weight was measured to the nearest $0.5 \mathrm{~cm}$ alongside the height after removal of shoes and wearing a light clothing only, using a mechanical beam balance mounted scale on the stadiometer. Body Mass Index (BMI), was calculated by putting the numbers related to height and weight in the equation $\left(\mathrm{wt} / \mathrm{ht}^{2}\right)$.

Waist Circumference was measured using a measuring tape, with measurement made halfway between the lower border of the ribs, and the iliac crest in a horizontal plane. Hip Circumference was measured at the widest point over the buttocks. For each of waist and hip circumference, two measurements to the nearest $0.5 \mathrm{~cm}$ was recorded. If the variation 
South American Journal of Academic Research

Special Edition May 2016

between the measurements was greater than $2 \mathrm{~cm}$, a third measurement was taken. The mean of the two closet measurements was calculated. Waist-to-Hip ratio (WHR) was calculated using the following equation WHR= waist circumference in $\mathrm{cm} /$ hip circumference in $\mathrm{cm}$ (Ahmad, 2012).

Flexibility was measured with the use of sit and reach box or flexibility box of $30.5 \mathrm{~cm}$ high. Have the client sat on the floor with legs together, knee extended, and sole of the feet placed against the edge of the box. The client was instructed to reach forward slowly and as far as possible along the top of the box while keeping the two hands parallel and to hold this position momentarily $(-2 \mathrm{sec})$. The researcher ensures that the knees do not flex and that the client avoids leading with one hand. The score in $\mathrm{cm}$ is the most distant point on the box contacted by the fingertips (Heyward, 2002).

Heart rate was measured with the use of palpation method on the radial artery which is located on the anterolateral aspect of the wrist directly in line with the base of the thumb. The tip of the middle or index finger was placed on the radial artery, stop watch was used to count for a set of 15 seconds, and the reading was multiply by 4 to obtained value of the beat per minute.

Blood Pressure was measured in a seated position after the participant had rested for at least $5 \mathrm{~min}$. A cuff of suitable size was applied to the participant's exposed upper arm, and was supported by the table at heart level. Blood pressure was measured with a standard Mercury Sphygmomanometer using the first and fifth korotkoff sound was recorded to the nearest $2 \mathrm{mmHg}$ (Dalton et al, 2001).

Aerobic endurance test was measured with the use of Queens's college step test which has a bench of height $16^{1 / 4}$ inch. The heart rate was calculated beginning $5 \mathrm{sec}$ after the cessation of exercise; take a 15 -sec pulse count. Multiply the 15 -sec count by 4 to express the score in beats per minute $(\mathrm{bpm}) . \mathrm{VO}_{2} \max$ in $\mathrm{ml} \cdot \mathrm{kg}^{-1}$ was estimated using the equation, for men, $\mathrm{VO}_{2} \max =111.33-(0.42$ X HR) (Heyward, 2002).

Muscle endurance was tested using Hand grip dynamometer. The individual stood erect, with the arm and forearm positioned as follows: shoulder adducted and neutrally rotated, elbow flexed at 90 degree, forearm in the neutral position, and wrist in slight extension ( 0 to 30 degree). The individual squeezed the dynamometer as hard as possible using one brief contraction and no extraneous body movement. Three trials were done for each hand, allowing a 1-min rest between trials, and the best score as the client's static strength (Heyward, 2002).

Both descriptive and inferential statistics was used to ascertain if any relationship exist between the Anthropometric parameters and physical fitness variables. Data obtained from each respondent was computed into Micro Soft Excel sheet (Version 2010) and then imported into SPSS data editor version 20. The statistical analysis was run to determine descriptive properties of each variable. Pearson Correlation coefficient was obtained for each relationship. Regression analysis was done which produced the regression equation that links variables and allow a specific prediction to be made .Observed difference was tested for any significance. The values of $\mathrm{R}, \mathrm{R}^{2}, \mathrm{~F}$, constant and slope was displayed on the table. Appropriate decision made, using $\alpha$ value of 0.05 . Null hypothesis was rejected if $t$ calculated $>\mathrm{t}$ critical $(\mathrm{p}=0.05)$, thereby upholding the alternative hypothesis. On the other hand, if $\mathrm{t}$ calculated $<\mathrm{t}$ critical $(\mathrm{p}=0.05)$, researcher fails to reject or retain the Ho.

Authors declare that there is no conflict of interest. Inform consent obtained for this study from departmental ethic committee for post graduate studies of University of Jos.

\section{Result}

TABLE 1: Descriptive Statistics for the Antropometric Parameters and Age

\begin{tabular}{llllll}
\hline & $\mathrm{X} \pm \mathrm{SD}$ & Min & Max & Skweness & Kurtosis \\
\hline Age (yr) & $35 \pm 7.12$ & 24 & 51 & 0.43 & -0.69 \\
Body weight $(\mathrm{kg})$ & $67 \pm 15.32$ & 42 & 94 & 0.33 & -0.86 \\
Body height (m) & $1.68 \pm 0.07$ & 1.54 & 1.85 & -0.09 & -0.16
\end{tabular}


South American Journal of Academic Research

Special Edition May 2016

\begin{tabular}{llllll} 
BMI $\left.\left(\mathrm{kgm}^{2}\right) \mathrm{m}\right)$ & $23.45 \pm 3.99$ & 16.0 & 31.1 & -0.02 & -0.69 \\
Waist circum $(\mathrm{cm})$ & $79.62 \pm 10.79$ & 60 & 102 & 0.29 & -0.47 \\
Hip Circum $(\mathrm{cm})$ & $87.19 \pm 13.34$ & 59 & 109 & -0.58 & -0.15 \\
WHR & $0.9 \pm 0.18$ & 0.71 & 1.47 & 2.51 & 5.99 \\
\hline
\end{tabular}

As shown in the table above, a total of 21 participants with visual impairment were used for the study, with their respective mean and standard deviation of their age and selected anthropometric parameters.

TABLE 2: Descriptive Statistics for the Physical Fitness Factors

\begin{tabular}{|l|l|l|l|l|l|}
\hline & $\mathrm{X} \pm S D$ & Min & Max & Skweness & Kurtosis \\
\hline Heart Rbeat $/ \mathrm{m}$ & $66.81 \pm 13.83$ & 49 & 96 & 0.59 & -0.58 \\
\hline BP Systolic(mmHg) & $130.10 \pm 19.96$ & 102 & 181 & 1.14 & 1.31 \\
\hline BP Diastolic(mmg) & $86.19 \pm 12.94$ & 64 & 120 & 1.02 & 1.48 \\
\hline Grip RT & $45.33 \pm 17.82$ & 18 & 77 & -0.15 & -0.89 \\
\hline Grip Lt & $51.10 \pm 16.06$ & 18 & 73 & -0.45 & -0.76 \\
\hline Flexibility(cm) & $22.21 \pm 8.93$ & 3.00 & 33.50 & -0.88 & -0.10 \\
\hline Aerobic Endu & $71.24 \pm 6.72$ & 56 & 83 & -0.29 & -0.12 \\
\hline
\end{tabular}

Table 3: Descriptive statistics showing the Impairment type

\begin{tabular}{|l|l|l|l|l|}
\hline & Frequency & Percent & Valid Percent & Cumulative Percent \\
\hline BLIND & 13 & 61.9 & 61.9 & 61.9 \\
\hline Low Vision & 8 & 38.1 & 38.1 & 100.0 \\
\hline Valid Total & 21 & 100 & 100 & \\
\hline
\end{tabular}

As shown in the table above, learners $(\mathrm{N}=21)$ with visual impairment that participated in the study are categorized into two- the blind and those with low vision; blind 13(61.9\%), low vision $8(38.1 \%)$.

Table 4: Linear Correlation Matrix between Anthropometric predictors and Physical Fitness Factors.

\begin{tabular}{|l|l|l|l|l|l|l|l|}
\hline $\begin{array}{l}\text { Predictor/independent } \\
\text { Antropometric } \\
\text { parameters }(\mathrm{X})\end{array}$ & $\begin{array}{l}\text { Heart } \\
\text { Rate } \\
\text { beat/min }\end{array}$ & $\begin{array}{l}\text { BP } \\
\text { Systolic } \\
\mathrm{mmHg}\end{array}$ & $\begin{array}{l}\text { BP } \\
\text { Diastolic } \\
\mathrm{mmHg}\end{array}$ & $\begin{array}{l}\text { Grip } \\
\text { Rt }\end{array}$ & $\begin{array}{l}\text { Grip } \\
\text { Lt }\end{array}$ & Flexibility & $\begin{array}{l}\text { Aerobic } \\
\text { Endurance } \\
\text { mlkg.min }\end{array}$ \\
\hline Body weight & .084 & $.443^{*}$ & .379 & .140 & .134 & .082 & -.124 \\
\hline Body height & .324 & .313 & .301 & .072 & -.090 & .044 & -.349 \\
\hline BMI & -.0 .062 & .398 & .338 & .163 & .232 & .044 & .027 \\
\hline WC & .190 & .229 & .257 & .119 & .097 & .277 & .014 \\
\hline HC & .010 & .235 & .147 & $.447 *$ & .412 & .043 & -.058 \\
\hline WHR & .136 & -.004 & .121 & -.378 & -.361 & .160 & -.058 \\
\hline
\end{tabular}

Correlation is significant at the 0.05 level (2-tailed).

Correlation is significant at the 0.01 level (2-tailed).

The table above shows the Pearson moment correlation coefficient of the linear relationship between the anthropometric parameters and physical fitness factors. The data showed no violation of normality, linearity or homoscedasticity.

\section{Research Question 1}

Is there any relationship between Body weight (BW) and Physical fitness of learners with visual impairment?

From the correlation matrix shown above in table 4, we identify the kind of association between Body weight as a predictor/independent parameter and various physical fitness factors such as Heart rate, systolic, diastolic, Rt grip strength, Lt grip strength, flexibility and Aerobic endurance- $\mathrm{p}=0.05 \mathrm{r}=.084, .443^{*}, .379, .140, .134, .082$ and -.0124 respectively. The scatter plot also buttresses how the points vary toward the imaginary line. There are 
South American Journal of Academic Research

Special Edition May 2016

positive and negative relationships as reflected in the table though it might be extremely weak or mild.

\section{Research Question 2}

Is there any relationship between body height (BH) and Physical fitness of learners with visual impairments?

From the same correlation table, the relationship between body height as an independent parameter to the physical fitness factors such as Heart rate, systolic, diastolic, Rt grip strength, Lt grip strength, flexibility and Aerobic endurance is established. The values are: $\mathrm{p}=0.05, \mathrm{r}=.324, .313, .301, .072,-.090, .044$ and -.349 respectively. The scatter plot of BH versus Aerobic endurance is shown in fig. 2. We have values both at either direction as well, as body height increases the grip Lt and aerobic endurance decreases while other Physical factors increases

\section{Research Question 3}

Is there any association between the Body Mass Index (BMI) and Physical fitness of learners with visual impairment?

Correlation table display the association between index of weight and height which is BMI (23.45 \pm 3.99$)$ to Heart rate, systolic, diastolic, Rt grip strength, Lt grip strength, flexibility and Aerobic endurance with both positive and negative values as $\mathrm{p}=0.05, \mathrm{r}=-.062, .398, .338$, $.163, .232, .044, .027$ respectively.

\section{Research Question 4}

Is there any relationship between Waist circumference (WC) and Physical fitness of learners with visual impairment?

The mean Waist circumference of the respondents is $79.6 \mathrm{~cm}$ and S.D of 10.79. Table of correlation gives the values of correlation coefficient between WC and Physical fitness factors (HR, BP Systolic, BP diastolic, grip Rt, grip Lt, flexibility and Aerobic endurance), at $\mathrm{p}=0.05 \mathrm{r}=.190, .229, .257, .119, .097, .277$ and .014 respectively. WC has a positive direction and correlation with all physical fitness factors.

\section{Research Question 5}

Is there any relationship between waist-to hip ratio (WHR) and Physical fitness factors?

From table of correlation matrix, WHR moves in a positive direction as the values of HR, BP diastolic, flexibility moves in a positive direction. On the other hand, WHR relationship has an inverse relationship with BP systolic, grip Rt and grip Lt.

It is essential to add that Hip circumference, which is an index used in calculating WHR has a positive correlation with all physical fitness factors except with Aerobic endurance of which the relationship is in a negative direction.

\section{Hypothesis 1}

There is no significant difference between the body weight and Physical fitness factors of learners with visual impairment. Ho: $u_{1}=u_{2}$

From table 4, computation of body weight versus respective physical fitness was correlated to see if any significant relationship exist. The rule is, if the calculated value displayed on the table is $\leq 0.05$, then there is statistical significant correlation between the two variables compared, this will make us to accept null hypothesis. On the other hand, if the calculated table value is $>0.05$ then there is no statistical significant correlation between the two variables, therefore enable us to reject the null hypothesis and upheld the alternative hypothesis .

For Body weight versus Heart rate, BP Systolic, BP diastolic, grip Rt, grip Lt and flexibility, the calculated values, at 2-tailed are $0.716,0.090,0.544,0.563,0.725$ and 0.124 respectively) for each relationship are found to be greater than $>0.05$. In the light of this, 
there is no statistical significant correlation between weight and Heart rate, weight and BP diastolic, weight and grip Rt, weight and grip left, weight and flexibility. This will make us to reject the null hypothesis that says, there is no significant difference between body weight and Heart rate, BP Systolic, BP diastolic, grip Rt, grip Lt and flexibility. We hereby upheld alternative hypothesis that says "there is a significant correlation between body weight and Heart rate, BP Systolic, BP diastolic, grip Rt, grip Lt and flexibility". This means that the computed test is in the rejection region.

From the same table 5, between body weight and BP systolic, the Calculated value $0.044<0.05$; there is statistical significant correlation between body weight and BP systolic. We here by failed to reject, that is accept/retain null hypothesis- "there is no significant correlation between BW and BP systolic. This means that the computed test is in acceptance region.

\section{Hypothesis 2}

There is no significant difference between the body height and Physical fitness of learners with visual impairment? Ho: $u_{1}=u_{2}$

From table 4, we can see that all calculated values of physical fitness factors using 2 tailed are found to be $>0.05$. In the light of this when there is no statistical significant correlation to upheld the null hypothesis on the relationship between body height and physical fitness variables, we conclude that the null hypothesis be rejected and retain the alternative hypothesis.

\section{Hypothesis 3}

There is no significant difference between the body mass index (BMI) and Physical fitness factors of learners with visual impairment. Ho: $u_{1}=u_{2}$

The 2 tailed values obtained from table 4 reveals that all calculated values are greater than 0.05 . As a result no statistically significant correlation between BMI and all physical fitness factors in this study, this enable the researcher to reject the null hypothesis and accept the alternative hypothesis. Since the relationship is not significant, any increase in BMI may not necessary means we must have same corresponding increase in physical fitness factors, Although any shift obtained will be in a positive direction positive.

Table 5 Model Summary for Regression

Predicting Heart Rate from various Anthropometric parameters

\begin{tabular}{llllllll}
\hline \multicolumn{9}{c}{ constant } & $\mathrm{a}$ & \multicolumn{1}{c}{$\mathrm{b}_{1}$} & $\mathrm{R}^{2}$ & sig. & $\mathrm{df}_{1}$ & $\mathrm{df}_{2}$ & linear regression equation \\
\hline $\mathrm{BW}$ & 61.684 & 0.076 & .007 & .716 & 1 & 19 & $\mathrm{HR}=61.684+0.076 \mathbf{B W}$ \\
$\mathrm{BH}$ & -31.373 & 58.178 & .104 & .152 & 1 & 19 & $\mathrm{HR}=-31.373+58.178 \mathbf{B H}$ \\
$\mathrm{BMI}$ & 71.818 & -.0214 & .004 & .790 & 1 & 19 & $\mathrm{HR}=71.818-0.214 \mathbf{B M I}$ \\
$\mathrm{WC}$ & 47.460 & .243 & .036 & .410 & 1 & 19 & $\mathrm{HR}=47.460+.234 \mathbf{W C}$ \\
$\mathrm{HC}$ & 65.861 & .011 & .000 & .964 & 1 & 19 & $\mathrm{HR}=65.861+.964$ HC \\
WHR & 57.545 & 10.003 & .018 & .556 & 1 & 19 & $\mathrm{HR}=57.545+10.003$ WHR \\
\hline
\end{tabular}

Table 5 comes by running a linear regression analysis which will predict physical fitness factor, (in this case heart rate) from various anthropometric parameters. The anthropometric parameters are the predictor (independent variable), while the heart rate is the dependent (criterion variable) that is being predicted. The constant $a$ and $b_{1}$ (slope of the straight line graph) value are inserted into the linear equation $y=a+b x$, where $x$ is the anthropometric variable to predict $y$. Equation connecting each anthropometric parameters are displayed on the table above.

For instance, to know what the heart rate will be when body weight is 50 . Using the relation $\mathrm{HR}=61.684+0.076 \mathrm{BW}$; $\mathrm{HR}=61.684+0.076 \times 50$; this gives 65.484 as the heart rate. Going back to the linear regression fit, when HR was plotted against the BW, we can see that the prediction equation really marks the point (y-axis) on the straight line, giving us the 
South American Journal of Academic Research

Special Edition May 2016

value of 65.5. This can be seen for other equation produced from respective anthropometric variables to obtain $\mathrm{HR}$.

To obtain equation that will connect all anthropometric variables in order to predict what Heart rate will be, a multiple linear regression was run and values of constant $\mathrm{a}$, and $\mathrm{b}$ (slope) was produced for each predictor. The equation is $\mathrm{HR}=-84.27+.12 \mathrm{BW}+.224 \mathrm{BH}-.718$ $\mathrm{BMI}+.467 \mathrm{WC}+1.158 \mathrm{HC}+1.135 \mathrm{WHR}$. Equation for other Physical fitness factors and independent predictors are shown in the table below:

Table 6 Multiple linear regression equation

\begin{tabular}{llllllll}
\hline \multicolumn{7}{c}{ Predictors/independent } \\
\hline Criterion/ & & $\mathrm{BW}$ & $\mathrm{BH}$ & $\mathrm{BMI}$ & $\mathrm{WC}$ & $\mathrm{HC}$ & WHR \\
Dependent & $\mathrm{a}$ & $\mathrm{b}_{1}$ & $\mathrm{~b}_{2}$ & $\mathrm{~b}_{3}$ & $\mathrm{~b}_{4}$ & $\mathrm{~b}_{5}$ & $\mathrm{~b}_{6}$ \\
HR & -84.276 & .12 & .224 & -.718 & -.467 & 1.158 & 1.135 \\
BP-Sys & 1049.874 & 6.030 & -1.8 & -3.45 & -.158 & -1.269 & -0.708 \\
BP-Dia & 213.433 & 3.886 & -1.446 & -3.115 & -2.971 & 3.963 & 3.878 \\
Grip Rt & -783.007 & -5.969 & 1.860 & 3.968 & 0.563 & 0.814 & -.160 \\
Grip Lt & -209.056 & -3.393 & 0.661 & 2.421 & 1.076 & -.125 & -.957
\end{tabular}

The researcher arrived at the following equations connecting various criterion variables (physical fitness factor) and all predictors (anthropometric parameters):

$$
\begin{aligned}
& \text { HR }=-84.27+.12 \mathbf{B W}+.224 \mathbf{B H}-.718 \mathbf{~ B M I}+.467 \mathbf{~ W C}+1.158 \mathbf{~ H C}+1.135 \mathbf{W H R} . \\
& \text { BP Systolic }=1049.874+6.030 \mathbf{B W}-1.8 \mathbf{B H}-3.45 \mathbf{B M I}-0.158 \mathbf{~ W C}-1.269 \mathbf{H C}- \\
& 0.708 \text { WHR }
\end{aligned}
$$

\section{Discussion of Results}

The discussion of the results in this section is carried out in line with the research variables, questions and hypothesis of this study. In assessing physical fitness, five components have been advocated by investigator to be essential (Heyward, 2000).

BMI is used as a crude index of obesity. Data from a report on obesity (WHO, 1998) explained a classification standard of overweight and obesity based on body mass index. Using this classification for the present study $4.76 \%$ of the learners with Visual impairment are underweight $(\mathrm{BMI}<18.5), 61.9 \%$ have normal weight (BMI 18.5-24.9), this constitute majority of the learners, $28.57 \%$ are overweight (BMI 25.0-29.9), the rest 4.76\% (BMI 30.034.9) have class 1 obesity. None of the students has class 2 (BMI 35.0-39.9) or class 3 (BMI $\geq 40.0$. Scientist agreed on the use of BMI in health risk appraisal assumes that people who are disproportionately heavy are so because of excess fatness. The mean BMI of the learner $23.5 \pm 3.99$ falls within the normal value. There is a prediction error of $\geq 5.0 \%$ which make some scientist to shine away from using BMI in estimation of obesity.

From table 4, we can see that BMI is related to physical fitness factors. It has an inverse relationship with HR and a positive relationship with both systolic and diastolic blood pressure, grip strength Lt and Rt and flexibility. The result is consistent with the findings of Fogelholm, Malmbers, Suni, Santilla, Kyrolaine and Mantyseari (2006).

In health related anthropometric measures in connection with physical fitness factor (Jaafari, 2012), he obtained a negative significant correlation between BMI and aerobic fitness. This does not agree with the present study where a positive non-significant relationship is obtained at both 0.01 and 0.05 level. Jafaari got the association at $\mathrm{p}=0.001$. His finding on if any relationship exist between BMI and flexibility is consistent with the present study $(\mathrm{r}=0.044)$, though the value shows a weak relationship. The mean Value of BMI obtained 23.45 \pm 3.99 when compared with other studies, was found to be lower than

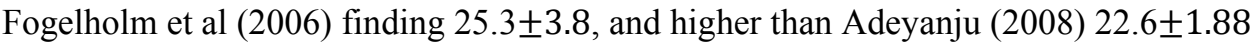

The Waist circumference and WHR can help us to distinguish between pattern of fat distribution in the upper and lower body. The measures are strongly associated with visceral fat and appear to be acceptable indexes of intra-abdominal fat (Depres et al. 1991). The 
national cholesterol Education Program (NCEP, 2001) recommends using waist circumference $(>100 \mathrm{~cm})$ for men and $>88 \mathrm{~cm}$ for women to evaluate obesity as a risk factor for coronary heart disease and metabolic diseases. In this study, the mean WC of learners with visual impairment is 79.62 , this shows that majority are not at risk of developing such diseases. Yet, only $4.8 \%$ might suffer such in the future.

The result obtained in the relationship between $\mathrm{WC}$ and aerobic fitness was positive and non-significant at alpha level of .05 respectively, this was inconsistent with Jafaari study where he obtained a negative and significant response at alpha level of 0.004 . The result obtained when WC is correlated with flexibility is highly consistent with Jafaari ( $\mathrm{r}=0.044)$. These point to the fact that when the waist is free of excess fat, activity of daily living will be much easier to perform. Common condition like arthritis, lumbago and radiculopathy will not be heard of.

In WHR, learners with visual impairment has an average value of 0.92 , this is within the standard value in young adults ( 0.94 for men and 0.82 for women). Any value above those quoted is at risk for adverse health consequences (Bray \& Gray, 1988). In this study, only $9.5 \%(\mathrm{~N}=2)$ of the learners might be affected if the WHR norm standardization reference Manual is used. On the relationship between WHR and physical fitness factor, the result of the study is consistent with Mohsei et al (2012) which shows that flexibility test do not demonstrate a significant correlation with WHR.

The maximum oxygen uptake $\left(\mathrm{VO}_{2} \mathrm{max}\right)$ is the most valid measure of functional capacity of the cardiorespiratory system; this is reflected in the capacity of the heart, lung and blood to transport oxygen to the working muscles and its utilization by the muscles during exercise. From the findings, the learners having a mean value of $71.24 \mathrm{ml} \cdot \mathrm{kg}^{-1} \cdot \mathrm{min}^{-1}$ (norm $49+$ ). This is reflected in the fact that most learners with visual impairment in this institution are not living a sedentary life. They are active participant in attending lectures and carrying out their daily activities.

When an individual is tested on two occasions and found to have a Systolic BP $\geq 140$ and a Diastolic BP $\geq 90$, such individual is hypertensive (National Committee on High BP, 1997). On the average, in the present study with the mean reading of BP $130 / 86$, it is assumed that the group is not hypertensive. On the other hand, taking a critical look, we found about $30 \%$ of the population is hypertensive with $1 \%$ at the stage III hypertension class. Hypertension has being found to be a risk factor for stroke and some debilitating eye conditions that could result in total blindness.

On the issue of grip strength, using the static strength norm, the population in this study has an average grip on the left hand, mean of 51 (norm: 43-55) while below average on the right hand, mean of 45 (norm: 41-47). Having low grip strength has a major health implication when carrying out daily living activity especially for right handed individuals.

\section{Summary of Finding}

1. Body weight is related to heart rate, diastolic blood pressure, Rt and Lt grip strength, flexibility and aerobic endurance.

On the other hand, there is no relationship between systolic blood pressure and body weight.

2. Body height is related to all physical fitness factors measured in this study

3. Body mass index is associated to heart rate, systolic and diastolic blood pressure, left and right grip strength, flexibility and aerobic endurance.

4. Waist circumference is related to all physical fitness factors measured in this study.

5. Hip circumference has a cordial relationship with HR, BP systolic and diastolic, left grip strength, flexibility and aerobic endurance but no association is found between hip circumference and right grip strength.

6. Waist- to hip- ratio is related to all physical fitness factor dealt with in this study. 
South American Journal of Academic Research

Special Edition May 2016

7. All relationship obtained are non-causal in nature. This means the association between the variables was not solely brought about by each of the variable, but factors not consider might be responsible for such relationship.

8. The relationship obtained between anthropometric parameters and physical fitness factors are extremely weak.

9. The result of waist circumference reveals that ample size among the group might probably (have the likelihood) develop hypertension coronary heart disease and metabolic disease in the near future.

10. The low grip strength among learners with visual impairment in this study on the right hand raises a point of concern.

11. From this study, various equations that connect individual anthropometric parameter and physical fitness factor(s) are predicted through both simple linear and multiple linear regression analysis.

12. Relationships obtained are of linear origin.

\section{Conclusion}

1. There is a linear relationship between anthropometric parameters and physical fitness factors.

2. It is possible to predict what each physical fitness factor(s) will be from anthropometric parameters.

3. The anthropometric equations obtained must be interpreted with care. It must not be generalized for all population outside this study. The population-specific anthropometric equations are valid for, and can be applied only to, individuals whose physical characteristics (age, gender, and level of body fatness) are similar to those in specific population sub group.

4. Anthropometric measurement to depict physical fitness is non-invasive, not expensive techniques. This should be made available for learners with and without visual impairment in this institution to alert those at danger list for major health problem.

\section{Recommendation}

1. Physical fitness program course should be incorporated into educational curriculum of all students including those with visual impairment in this university.

2. Health related Physical fitness level of learners should be given priority, the Rehabilitation Laboratory of the Special Education Department should be well equipped to enable student to have access to the equipment's.

3. Physical activity level of visual learners can be improved by introducing adaptive exercise strategies.

\section{Limitation of the Study}

1. The study is limited to the linear relationship between anthropometric parameters and physical fitness factors of male learner with visual impairment at the University of Jos.

2. The sample size $(\mathrm{N}=21)$ was less and this may affect generalization.

\section{Suggestions for further Study}

1. Studies should be carried out to ascertain nonlinear relationship between anthropometric parameters and physical fitness factors.

2. Studies should be carried out using female learners with visual impairment.

3. Studies should be done to ascertain differences in relationship between anthropometric parameters in learners with and without visual impairment involve in sport activities. 
4. Subsequent studies may include measurement of body composition using skin fold techniques (Caliper) to ascertain the percentage level of fat.

5. Interested researcher must increase the sample size to ascertain relationship between the variables of anthropometric and physical fitness.

6. Further studies should consider true experimentation and probability sampling techniques.

\section{Contribution to Knowledge}

This study has contributed to the knowledge base of general and special teachers on learners with visual impairment especially on their health related physical fitness. They have also seen how noninvasive anthropometric indices can be used to predict physical fitness.

Secondly, the curriculum planner has seen the need to incorporate physical fitness program when writing syllabus or curriculum for the learners with visual impairment.

Health professional role has been expanded in that routine counseling must be given to learners with visual impairment on the maintenance of regular physical activity.

The study has opened a new trend in research for special educators on physical activity measurement for learners with visual impairment.

Finally, Family has greatly benefited as adaptation in both physical and social engagement will be in place for their family members who are visually impaired.

\section{References}

[1] Adeyanju, E.S.(2008). Morphological and Physiological Characteristics of FCE Kano female soccer players to the 2007 MCEGA Games. Journal of Education, 1(1), 225-231

[2] Ahmad, A., Mohsen, A.B., Mohammad, D., Alimardani, M.(2012).Relationship between physical fitness and anthropometric indicators in non-athlete students. Annuals of Biological Research, 3(9), 4617-4621. www.scholarresearchlibrary.com

[3] American College of Sport Medicine (ACSM). (2000). ACSM's guidelines for exercise testing and prescription. Philadelphia: Lippincott Williams \& Wilkins.

[4] Awotunde, P.O. \& Ugodulunwa, C.A. (2004). Research methods in education. (Rev. ed.) Jos Fab Anieh Nigeria Ltd.

[5] Blessing, D.L., \& McCrimmon, D. (1993). The effect of regular exercise program for visually impaired adsighted school children. Journal of visual impairment \& Blindness, 87, 50-52.

[6] Bray, G.A. \& Gray, D.S.(1988). Obesity: Part 1-Pathogenesis. Western Journal of Medicine 149:

429-441.

[7] Bueli, C.E. (1982). Physical education and recreation for the visually Handicapped. Reston, VA: American Alliance for Health, Physical Education, Recreation and dance.

[8] Colak, T., Bamac, B., Aydin, M., Mreic, B., \& Ozbek, A.(2004).Physical fitness levels of blind and visually impaired goalball team players. Isokinetics and exercise science, 12,247-252.

[9] Copper Institute for Aerobics Research. (1997). The Physical Fitness specialist certification manual. Dallax Texas: USA.

[10] Crespo, C.J., Ainsworth, B.E., Keteyian, S.J., Health, G.W., \& Smith, E. (1999). Prevalence of physical inactivity and its relation to social class in U.S adults. Results from the third National Health and Nutrition Examination survey, 1888-1994. Medicine \& Science 31: 1821-1827.

[11] Dalton, M., Cameron, A.J., Zimmet, P.Z., Shaw, J.E., Jolley, D., Dunstan, D.W., \& Welborn, T.A. (2003).Waist circumference, waist-hip ratio and body mass index and their correlation with cardiovascular disease risk factors in Australian adults. Journal of internal medicine, 254,555-563.

[12] Depres, J.P., Prud'homme, D., Pouliot, M. C., Tremblay, A., \& Bouchard, C. (1991). Estimation of deep adipose- tissue accumulation from simple anthropometric measurements in men. American Journal of Clinical Nutrition, 54: 471-477.

[13] Fogelholm, M., Malmberg, J., Suni, J., Santtila, M., Kyrolainen, H., \& Mantysaari, M.(2006).Waist circumference and BMI are independently associated with the variation of cardio-respiratory and neuromuscular fitness in young adult men. International Journal of Obesity, 30,962-969. 
South American Journal of Academic Research Special Edition May 2016

[14] Heyward, V.H. (2002). Advanced Fitness Assessment and Exercise Prescription. $4^{\text {th }}$ Ed. Burgess Publishing company.IL: USA.

[15] Hopkin, W.G., Gaeta, H., Thomas, A.C., \& Hill, P.McN.(1987).Physical fitness of blind and sighted children. Eur J Appl Physiol, 56,69-73.

[16] Jaafari, L.(20012).Health-related anthropometric measures in connection with physical fitness factors. IPEDR, 31,21-24.

[17] Thylefor B, Negrwel AD, Pararajasegaram R, (1995). Global Date in Blindness Bull WHO 1995; 73 : 115 21

[18] Lieberman, L.J.(2002).Fitness for individual who are visually impaired or deaf blind. Helen Reid educational foundation 34 (1),13-8023.

[19] Lieberman, L.J., \& McHugh, E.(2001). Health-related fitness of children who are visually impaired. Journal of visual impairment, 5,272-287.

[20] National Committee on High Blood Pressure.(1997). Data from the $6^{\text {th }}$ report on detection, evaluation and treatment of high blood pressure. NIH Publication No. 98-4080.

[21] New king James Bible.(2000). For bodily exercise profited little. 1 Timothy Chapter 4 verse 8.

[22] National Cholesterol Education Program. NCEP. (2001). Executive summary of the third report of the National Cholesterol Education Program expert panel on detection, evaluation and treatment of high blood cholesterol in adults. Journal of the American Medical Association, 285: 2486-2497.

[23] Pratt, M., Macera, C., \& Blanton, C. (1999). Levels of physical activity and inactivity in children and adullts in the United States: Current evidence and research issues. Medicine \& Science in Sports \& Exercise 31 (Suppl.): S526-S533.

[24] U.S Department of Health and Human Services. (1996).Physical activity and health: A report of the Surgeon General. Atlanta,GA: U.S Center for Disease Control, Prevention and Health Promotion.

[25] Wang, Z.M, Pierson R.N., Heymsfield, S.B.(1992). The five-level model: a new approach to organizing bodycomposition research. American Journal of Clinical Nutrition. 56: 19-28

[26] WHO Working Group. (1986). Use and interpretation of anthropometric indicators of nutritional status. Bulletin of the World Health Organization. 64: 929-941. ries 854

[27] WHO (1995). Report of WHO Expert Committee. WHO Technical Report Series 854.

[28] WHO Report.(1998). Obesity: Preventing and managing the global epidemic. Report of a WHO consultant on Obesity. Geneva: World Health Organization.

[29] Zenic, N., Foretic, N., \& Blazevic, M.(2013).Nonlinear relationship between anthropometric and physical fitness variables in untrained pubescent boys. Coll Antropol, 37(2),153-159. 